\title{
Ciencias "ómicas", ¿cómo ayudan a las ciencias de la salud?
}

\author{
Maria E. Frigolet y \\ Ruth Gutiérrez Aguilar
}

\begin{abstract}
Resumen
Las "ómicas" son las ciencias que permiten estudiar un gran número de moléculas, implicadas en el funcionamiento de un organismo. En las últimas décadas, el avance tecnológico ha permitido el estudio a gran escala de muchos genes, proteínas y metabolitos, permitiendo la creación de la genómica, proteómica, metabolómica, entre otras. Cada una de estas áreas ha ayudado a un mejor entendimiento de la causa de ciertas enfermedades. Además, la aplicación del conocimiento sobre las "ómicas" a la clínica podrá utilizarse para hacer un diagnóstico más temprano o para prevenir el desarrollo de una enfermedad. Así, la medicina se podrá convertir en medicina personalizada, donde cada individuo llevará un tratamiento para una determinada enfermedad acorde a su información genética y a su medio ambiente. En este artículo se define a cada una de las "ómicas", la metodología que se usa para su análisis y un ejemplo de su aplicación clínica.
\end{abstract}

Palabras clave: ácido desoxirribonucleico (ADN), ácido ribonucleico (ARN), proteínas, metabolitos, ciencias "ómicas".

\section{The "omics" sciences, how does this help health science?}

\begin{abstract}
"Omics" are defined as a group of disciplines that aim to collect a large number of biological molecules involved in the function of an organism. In the last decades, technological evolution allowed us to better understand global changes in genes, proteins and metabolites, giving rise to genomics, proteomics, metabolomics, among others. These fields have contributed to the generation of knowledge regarding the cause of diseases. The application of the "omics" to the clinics could help diagnose or prevent certain diseases. In the future, treatment will be specific for each patient according to their genetical background and environment exposure, creating personalized medicine. This article defines every "omic", the technological tools used for its analysis, and examples of its clinical applications.
\end{abstract}

Key words: DNA (deoxyribonucleic acid), RNA (ribonucleic acid), proteins, metabolites, "omics" sciences. 


\section{Maria Eugenia Frigolet Vázquez Vela}

maruf.himfg@gmail.com

Realizó una estancia postdoctoral en la Universidad de Toronto y el Hospital Mount Sinai en Toronto, Canadá, especializándose en la acción de la insulina en adipocitos. Obtuvo el grado de maestría y doctorado con mención honorífica en Ciencias Bioquímicas por la Universidad Nacional Autónoma de México (UNAM); es licenciada en Nutrición y Ciencia de los Alimentos por la Universidad Iberoamerciana.

Actualmente es investigadora en Ciencias Médicas en el Laboratorio de Enfermedades Metabólicas: Obesidad y Diabetes del Hospital Infantil de México "Federico Gómez" y es miembro del Sistema Nacional de Investigadores, nivel 1. Ha publicado 12 artículos, los cuales han sido citados más de 400 veces. Sus principales temas de investigación se centran en los efectos metabólicos de ciertos nutrimentos sobre el metabolismo del tejido adiposo y en la influencia de la cirugía bariátrica sobre el metabolismo humano.

\section{Ruth Gutierrez-Aguilar}

ruthgutz@unam.mx

Realizó una estancia postdoctoral en el Instituto de Enfermedades Metabólicas de la Universidad de Cincinnati, Estados Unidos. Es doctora en Genética Humana en Obesidad y Diabetes tipo 2 en la Universidad de Lille 2 en Francia. Estudió la maestría de Ciencias Bioquímicas en la Facultad de Química de la UNAM, obteniendo la Medalla Alfonso Caso, donde también estudió la licenciatura de Química en Alimentos.

Es parte de la Unidad Periférica de la Facultad de Medicina de la UNAM ubicada en el Hospital Infantil de México "Federico Gómez" y es responsable del Laboratorio de Enfermedades Metabólicas: Obesidad y Diabetes. Forma parte del Sistema Nacional de Investigadores, nivel 1 y ha publicado 22 artículos con más de 700 citas. Sus líneas de investigación incluyen la descripción de la función de nuevos genes asociados a la obesidad, la metabolómica de la obesidad y la influencia de ciertos nutrimentos/medicamentos sobre la fisiología y metabolismo animal. 


\section{Introducción}

\section{Historia del ADN}

Toda la información genética que heredamos de nuestros padres se encuentra en el genoma, que está formado por el ácido desoxirribonucleico (ADN) y que se localiza en el núcleo de las células de nuestro organismo. El ADN, que mide aproximadamente dos metros de longitud, se superenrolla para caber en el núcleo que mide seis micras. Para esto, el ADN se ordena en cromosomas, de los cuales el ser humano tiene 22 pares de somáticos y un par de los sexuales (cromosomas $X$ y $Y$ ).

\section{6 \\ En los años 1980, el término "ómica" se acuñó para referirse al estudio de un conjunto de moléculas.}

En 1944, Oswald Avery, Colin MacLeod y MacLyn McCarty descubrieron que el ADN es el "principio de transformación" o material genético (Avery, MacLeod y McCarty, 1944). Sin embargo, la comunidad científica de aquella época exigía más información sobre dicho material genético, por lo cual, diversos investigadores continuaron en la búsqueda de pruebas y fueron Alfred Hershey y Martha Chase (1952) quienes demostraron definitivamente que el ADN es la molécula que guarda la información genética heredable. Posteriormente, en 1953, Watson y Crick describieron la estructura del ADN, la cual está formada por dos cadenas complementarias que se unen en direcciones inversas (1953). Sin embargo, fue hasta 1977, que se logró decodificar o secuenciar por primera vez el ADN, lo cual quiere decir que se estableció el orden de los nucléotidos de un fragmento de ADN. Esto asentó los fundamentos para el análisis y secuenciación del genoma. Sin embargo, debido al desarrollo científico y tecnológico que se logró en los años siguientes, fue que en 2001 se logró secuenciar el genoma humano (Venter et al., 2001).

\section{Dogma central de la biología molecular}

Se conoce como el dogma central de la biología molecular a la forma como fluye la información genética del ADN, desde su paso por el ácido ribonucleico mensajero (ARNm) y hasta llegar a las proteínas.

El ADN está formado por la unión de nucleótidos formados por bases nitrogenadas (adenina, guanina, citosina, timina), un azúcar (desoxirribosa) y ácido fosfórico. La combinación de estos nucléotidos da origen a los genes, los cuales 
Figura 1.

El ADN es como una archivero que contiene la información que el mensajero distribuye para que se lleve a cabo la síntesis de proteínas (o que actúe el obrero). guardan la información genética. A partir de los genes, se lleva a cabo la transcripción, mecanismo por el cual el ADN se convierte a ARNm. Finalmente, la traducción permitirá que el ARNm se convierta en una proteína.

Por lo tanto, se puede decir que el ADN es un archivero en el que se guarda toda la información. El ARNm es el mensajero que lleva la información del archivero a donde se va a utilizar. Finalmente, esa información es utilizada por los obreros, correspondientes a las proteínas (véase figura 1). Cabe mencionar que el ADN se replica para que a partir de una célula madre, se generen dos células hijas conteniendo el mismo material genético.
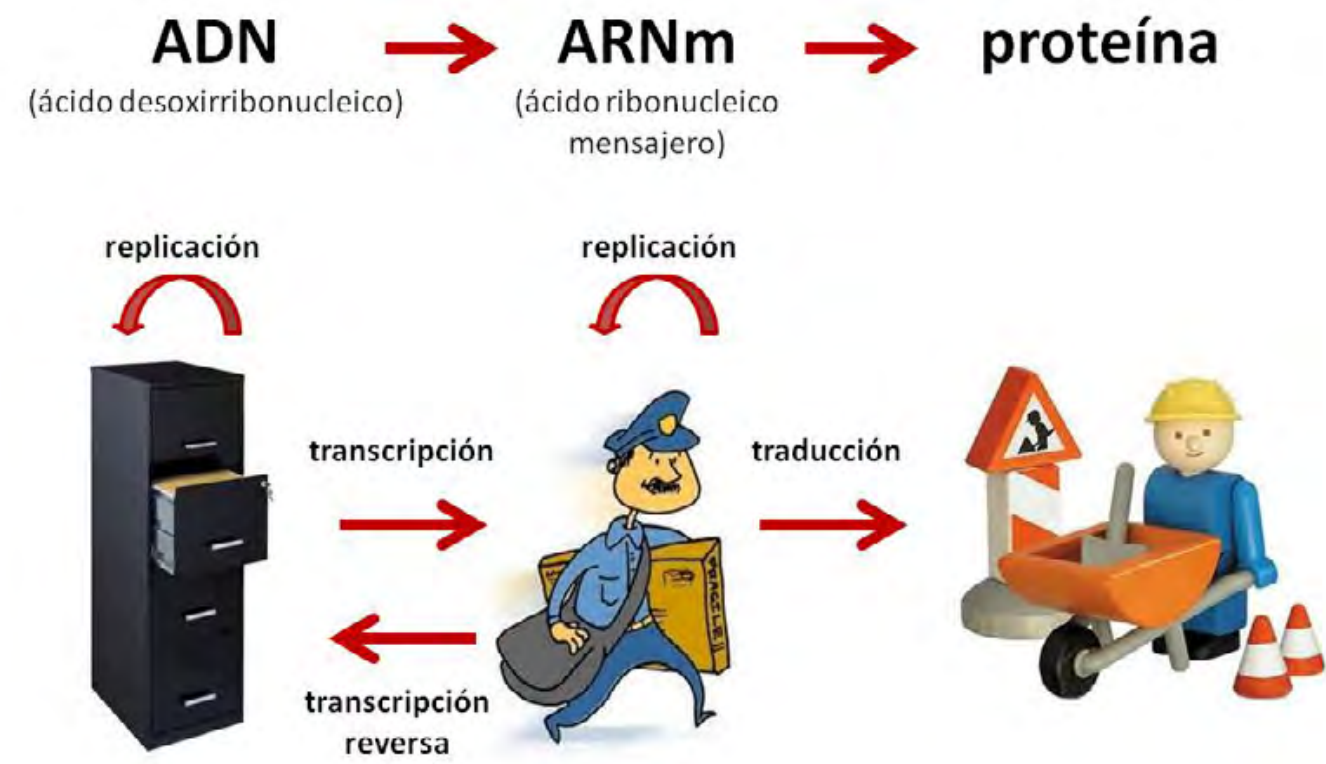

Un gen es un fragmento de ADN que contiene la información genética. Las regiones que separan a los diferentes genes se llaman regiones intergénicas. Un gen está conformado por diversas partes como el promotor, exones e intrones, principalmente. El promotor es la secuencia del gen que es reconocida por la maquinaria de transcripción para convertir el ADN a ARNm. LoS exones son las secuencias del ADN que dan origen a la proteína. Estos exones pueden estar interrumpidos por los intrones, que son regiones que pueden regular la transcripción de los genes. El ARNm maduro sólo estará formado por la secuencia de los exones, la cual va a ser traducida para sintetizar una proteína (véase Figura 2). 
Figura 2 Los exones se traducen para sintetizar las proteínas.

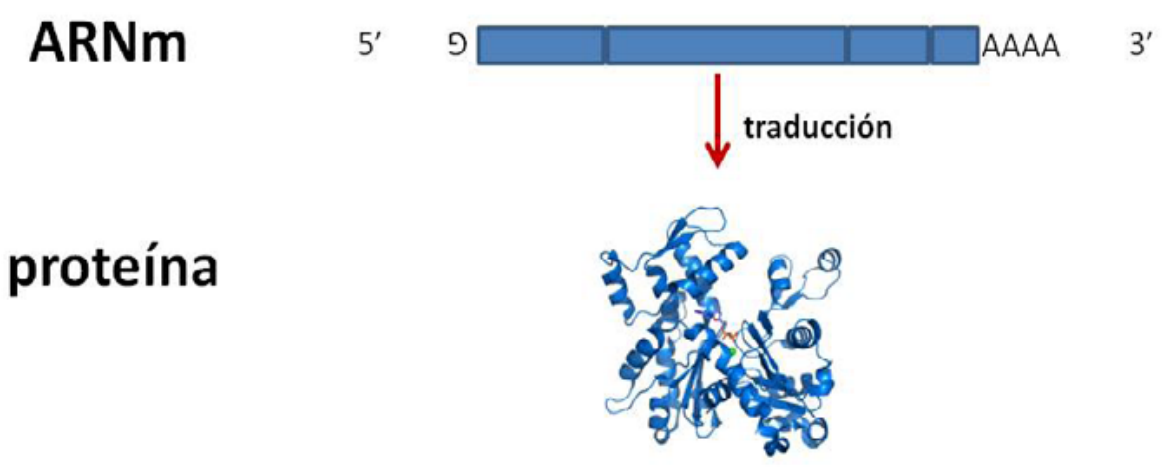

El ADN se encuentra en todos los núcleos de las células del organismo y es exactamente el mismo, por lo que, se puede extraer ADN de la sangre, cabello, saliva o cualquier célula, obteniendo la misma información genética. Sin embargo, el ARNm es diferente, ya que a partir del ADN que tienen todas las células, se transcribe solamente el ARNm que necesita una célula determinada, para posteriormente ser traducido a la proteína que ejercerá la función en dicha célula. Por lo tanto, el ARNm y las proteínas son dinámicas y son específicas de tiempo, tratamientos y de células.

El ADN del humano está formado por tres billones de nucleótidos que contiene alrededor de 30000 a 40000 genes, donde entre 1 y 2\% del genoma son regiones codificantes y el resto no codifican para una proteína, pero regulan la presencia del ARNm o expresión de los genes (Harrow et al., 2012).

\section{"Ómicas": generalidades de análisis de muchos datos}

En los últimos años ha existido un gran avance en el desarrollo de la tecnología, lo cual ha provocado que se generen equipos analíticos que logran identificar y medir muchas moléculas. Esto ha ido de la mano con la creación de grandes computadoras, que permiten el almacenamiento de gran cantidad de información, de igual manera, el desarrollo de software ayuda al análisis de los datos generados. Todo esto ha dado como resultado el análisis de diferentes moléculas (ADN, ARN, proteínas, etcétera) y la creación de redes de interacción 
1. Para mayor información, revisar la página http://omics.org. entre ellas para comprender con más exactitud a los sistemas biológicos complejos.

En los años 1980, el término "ómica" se acuñó para referirse al estudio de un conjunto de moléculas. Por ejemplo, genómica se refiere al estudio de muchos genes en el ADN; transcriptómica es el estudio de muchos transcritos o ARNm; proteómica es el estudio de muchas proteínas; metabolómica es el estudio de muchos metabolitos, entre otros. ${ }^{1}$

Antes, los químicos y biólogos realizaban la parte experimental de su investigación y análisis de una o pocas moléculas que se podían estudiar en laboratorios. Gracias al avance de la tecnología y de las herramientas de análisis, se incrementó el número de moléculas detectables al mismo tiempo, por lo que se han formado grupos multidisciplinarios constituidos por biólogos, químicos, médicos, programadores, bioinformáticos, bioestadísticos, que juntos colaboran para la interpretación de todos los datos recabados.

Al aumentar el número de moléculas a analizar fue necesario acrecentar también el tamaño de muestra para mantener un poder estadístico válido. Es por esto que se crearon biobancos tales como el de UK Biobank (biobanco del Reino Unido), para el cual se reclutaron a 500000 individuos y se tomaron muestras de sangre, orina y saliva para su análisis posterior. Este tipo de biobancos ayudará a las diversas disciplinas "ómicas" en su estudio de las enfermedades para mejorar el diagnóstico, prevención y tratamiento de las mismas.

A continuación, se describe brevemente lo que estudia cada "ómica", así como la metodología empleada para su análisis y alguna aplicación en la clínica. Es importante hacer notar que los datos que se obtienen de cada una no nos permiten conocer completamente un sistema biológico. Sólo la integración de varias de éstas y la relación que existe entre ellas, nos es útil para conocer globalmente a dichos sistemas.

\section{Genómica}

La genómica fue la primera "ómica" en crearse, esta ciencia se encarga del estudio del genoma o ADN. Anteriormente, la tecnología permitía estudiar pocos genes, así como sus cambios o mutaciones, a lo que se le denominaba genética. Sin embargo, la tecnología avanzó y a principios del siglo XXI se reportó la secuencia del genoma humano (Venter et al., 2001), lo que quiere decir que se descifró el orden de todos los nucleótidos contenidos en el ADN del humano (International Human Genome Sequencing Consortium, 2004). La secuencia del genoma reveló que 99\% del genoma entre humanos es el mismo y sólo 1\% es diferente. Estas diferencias son Ilamadas variantes de un solo nucleótido (SNV por sus siglas en inglés), anteriormente llamados polimorfismos de un solo 
Figura 3.

Poliformos de un solo nucleótido.

nucleótido o SNP (véase figura 3). Estas variantes son frecuentes y confieren susceptibilidad o protección para desarrollar enfermedades.

SNV

Alelo 1

Alelo 2
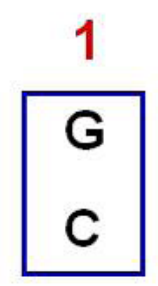

2

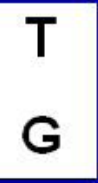

Anteriormente, se estudiaban fragmentos de ADN y su localización en los diferentes cromosomas por medio de metodologías de hibridación in situ con fluorescencia (FISH). De esta forma era posible señalar cierto fragmento del ADN, conteniendo uno o varios genes, el cual era el causante de una enfermedad, debido a la depleción, duplicación, inversión y translocación cromosómica de dicho fragmento de ADN. Posteriormente, surgió la secuenciación con el método Sanger que consiste en replicar la región del genoma de interés por medio de cebadores específicos y utiliza dideoxinucleótidos marcados radioactivamente que posteriormente evolucionaron a marcaje fluorescente. Estos nucleótidos marcados al ser incorporados en la nueva cadena amplificada, finalizarían la reacción permitiendo conocer el último nucleótido de dicha reacción y establecer la secuencia del ADN. Esta metodología se desarrolló en los la década de 1970 y se acopló a estrategias de secuenciación a gran escala, lo que permitió realizar la secuenciación del genoma humano en 2001; sin embargo, estas metodologías eran muy costosas.

El avance de la tecnología ha permitido crear nuevos métodos para reducir costos y obtener secuenciaciones masivas, creando la "secuenciación de siguiente generación", volviendo más accesible su uso. En la actualidad es posible elegir qué regiones del genoma se desean secuenciar. Por ejemplo, a partir del ADN de un individuo se puede secuenciar el genoma completo, solo exones o regiones específicas del genoma (genes), con la finalidad de encontrar la región del genoma que pudiera estar afectada o mutada y ser la posible causante de alguna enfermedad.

Por otra parte, el descubrimiento de las variantes de un solo nucleótido originó que se desarrollaran otras metodologías para su identificación, como la llamada genotipificación. La genotipificación consiste en amplificar el ADN y añadir a la reacción una sonda (fragmento de 25 nucleótidos) que se pueda hibridar o unir a la variante de nuestro interés y así obtener el genotipo del individuo.

La genotipificación se puede realizar para pocas variantes de forma individual o en conjunto. Sin embargo, en la última década la tecnología desarrollada permite analizar hasta dos millones de variantes al mismo tiempo para cada 
individuo. Esta tecnología generó la creación de los estudios de asociación del genoma completo (genome wide association studies, GWAS). Estos estudios permiten comparar millones de variantes entre cohortes de casos y controles, resultando en la asociación de algunas variantes con la enfermedad de interés. El gran avance tecnológico, la creación de consorcios de bancos de ADN de miles de muestras de humanos, el apoyo de herramientas estadísticas y la referencia del genoma humano ha permitido descubrir variantes raras o comunes que contribuyen al desarrollo de una enfermedad (Begum et al., 2012; LaFramboise, 2009; Manolio, 2010). Sin embargo, la función de muchas de esas variantes y de los genes aledaños no se conoce (Gutiérrez et al., 2011), lo que abre el horizonte para explorar nuevas vías para entender mejor la causa de las enfermedades.

Por otra parte, la genética ha ayudado a describir enfermedades que son heredables con un patrón mendeliano, las cuales generalmente contienen mutaciones (poco frecuentes) en la parte que codifica un gen, provocando que haya un cambio funcional de la proteína y que se presente la enfermedad (por ejemplo, fibrosis quística). Sin embargo, hay enfermedades que no siguen el patrón mendeliano y se les conoce como enfermedades comunes. Es aquí donde la genómica ha permitido describir muchas variantes que están asociadas a alguna enfermedad, por ejemplo: obesidad y diabetes. Las variantes asociadas a enfermedades comunes son frecuentes (a diferencia de las mutaciones) y se presentan en regiones regulatorias de los genes y conceden susceptibilidad o protección para el desarrollo de la enfermedad.

Existen algunas limitantes de los estudios genómicos como son las siguientes: primero, las variantes asociadas a una enfermedad explican solamente una pequeña parte del componente heredable; en segundo lugar, las variantes pueden ser reguladas por factores ambientales independientemente de la secuencia del ADN (ver epigenómica). Es por esto que la genómica ofrece correlaciones entre las enfermedades y las variantes génicas, sin demostrar cómo esa variable puede ser causal de la enfermedad. Entonces, es necesario integrar estas correlaciones con otras "ómicas" para encontrar la función de los genes y de las variantes que los modulan, para comprender mejor la causa de la enfermedad.

\section{Transcriptómica}

El ADN se transcribe a ARNm y a éste le llamamos también transcrito. La transcriptómica es la "ómica" que se encarga de estudiar la expresión de los transcritos que provienen de diferentes genes. El ARNm es específico de cada célula y de las condiciones fisiopatológicas en determinado momento. Por ejemplo, el ARNm extraído de células del músculo será diferente a las células del hígado antes y después de comer. Es por esto que la transcriptómica se hace en tejido y en tiempo específico, ya que la transcripción es muy dinámica. 
Anteriormente, se creía que gran parte del ADN que no se transcribía a ARNm, no tenía ninguna función y se consideraba ADN "basura." Sin embargo, además del ARNm existen otros transcritos no codificantes como son: 1) los miRNA (micro ARN, secuencias de 21-25 nucleótidos) y, 2) los IncRNA (ARN largos no codificantes, $>200$ ). Estos tipos de transcritos no codificantes tienen como función regular la expresión de los ARNm codificantes. Por lo tanto, sabemos en la actualidad que estas regiones del ADN son secuencias reguladoras de la expresión de diversos genes y no son "basura".

Las metodologías que se utilizan para analizar el ARNm son: 1) microarreglos o 2) secuenciación del ARN (RNAseq por sus siglas en inglés). Los microarreglos consisten en hibridar el ARNm de un determinado tejido a secuencias de genes previamente conocidos que se encuentran unidas a un microarreglo. De esta forma, se pueden hacer comparaciones entre casos o controles o simplemente ver qué genes se expresan mayoritariamente en ciertas condiciones. En cambio, el RNAseq consiste en secuenciar todos los transcritos presentes en esas condiciones, teniendo como consecuencia encontrar nuevos transcritos que no se conocían anteriormente y nuevos genes involucrados en un padecimiento.

En la actualidad, una de las aplicaciones de la transcriptómica es el análisis de la expresión de genes implicados en diferentes tipos de cánceres. Por ejemplo, en México se ha utilizado el microarreglo Oncotype RX, el cual mide la expresión de 21 genes involucrados en el cáncer de mama, para mejorar la toma de decisiones del tratamiento por parte del clínico tratante. Los resultados mostraron que al aislar el ARNm de una biopsia del tumor de mama e hibridándolo al microarreglo aumentó la expectativa de vida de los pacientes y redujo los costos de la enfermedad (Bargalló-Rocha et al., 2015).

\section{Proteómica}

El ARNm es traducido a proteínas (formadas por aminoácidos), las cuales están encargadas de realizar la función correspondiente del gen. La proteómica se encarga de estudiar muchas proteínas presentes en una muestra.

Una vez que las proteínas son traducidas pueden sufrir modificaciones post-traduccionales, tales como cortes, fosforilación, glucosilación, sumolización. Estas modificaciones provocan cambios estructurales que controlan la formación de complejos funcionales proteicos, regulan la actividad de las proteínas y las transforman en formas activas o inactivas. Algunos de estos cambios son señales para la estabilidad o degradación de las proteínas. La proteómica estudia a las proteínas, así como las modificaciones post-transcripcionales que las regulan. Al igual que el ARNm, las proteínas se expresan en tejido y tiempo específico, por lo que la toma de la muestra dependerá del tejido y del estadio de la fase celular de interés. 
La metodología para estudiar la proteómica consiste principalmente en: 1) separar las proteínas por técnicas cromatográficas (líquidos, gases, etcétera) o electroforéticas (2D-PAGE); 2) digerir las proteínas; 3) detectar los fragmentos peptídicos (de proteínas) por espectrometría de masas, y 4) identificar las proteínas.

La aplicación de la proteómica a la clínica se encuentra en etapas tempranas; sin embargo, actualmente se utiliza para: a) identificación de proteínas en una muestra biológica; b) identificación de un perfil de proteínas comparando muestras entre casos y controles; c) determinar la interacción entre diversas proteínas y su red funcional, y d) identificar las modificaciones post-transcripcionales (Mishra, 2010). De esta forma, se lograrán encontrar biomarcadores (proteínas) que sirvan para diagnosticar enfermedades, con el fin de dar un tratamiento más adecuado en un futuro.

El gran esfuerzo de muchos científicos ha logrado crear el Proyecto del Proteoma Humano, que proporciona una lista de proteínas que se han encontrado en diferentes tipos celulares y órganos de adultos o de fetos. Estos datos son públicos y reporta más de 30000 proteínas identificadas en el humano (Omenn et al., 2015).

El uso de la proteómica lo podemos ver en diferentes enfermedades como son: cáncer, diabetes, obesidad, entre otras. Por ejemplo, dentro del ámbito de la reproducción asistida, la proteómica ha sido de gran interés para analizar los gametos (óvulos y espermatozoides) e identificar proteínas que puedan ser utilizados como biomarcadores para poder seleccionar aquellos gametos que aseguren una mejor fertilización y aumentar la tasa de éxito de la reproducción asistida (Kosteria et al., 2017).

\section{Metabolómica}

Los metabolitos son aquellas moléculas que participan como sustratos, intermediarios o productos en las reacciones químicas del metabolismo. La metabolómica se define como una tecnología para determinar los cambios globales en la concentración de los metabolitos presentes en un fluido, tejido u organismo en respuesta a una variación genética, a un estímulo fisiológico o patológico (Park, Sadanala y Kim, 2015). La metabolómica nos permite analizar el perfil metabólico de una muestra, de forma cuantitativa y cualitativa. La metodología utilizada es la misma que la descrita en proteómica, en la que se pueden encontrar metabolitos específicos relacionados con el desarrollo de una enfermedad o con la respuesta a un tratamiento nutricio o farmacológico.

Recientemente, se ha logrado avanzar de forma importante en el conocimiento de la metabolómica de la obesidad y la diabetes, al asociar la concentración de ciertos metabolitos en suero y orina con un mayor riesgo de desarrollar 
dichas enfermedades. Estos metabolitos incluyen a varios aminoácidos, lípidos, hidratos de carbono y ácidos nucleicos.

En condiciones de obesidad, la concentración circulante de algunos aminoácidos, especialmente los de cadena ramificada (isoleucina, leucina y valina), está elevada (Chevalier et al., 2005). En población infantil mexicana se logró asociar un perfil de aminoácidos (mayor concentración de arginina, leucina/isoleucina, fenilalanina, tirosina, valina y prolina) con obesidad, con lo cual se tiene la capacidad de predecir un mayor riesgo de hipertrigliceridemia en los siguientes dos años (Moran-Ramos et al. 2017).

Por otro lado, la obesidad se caracteriza por la presencia elevada de ácidos grasos libres en suero. De hecho, se ha visto que la concentración de ácido oleico, palmítico, palmitoleico y esteárico es elevada, mientras que la concentración de etanolamina y lisofosfatidiletanolamina se encuentra disminuida en organismos obesos (Moore et al., 2014). Aunados a los ácidos palmítico, palmitoleico y esteárico, las ceramidas y el diacilglicerol son metabolitos que se encuentran aumentados en pacientes diabéticos (Fiehn et al., 2010). En lo que se refiere a los hidratos de carbono, se ha observado que los pacientes con obesidad y diabetes tienen concentraciones aumentadas de glucosa, fructosa y glicerol en suero (Fiehn et al., 2010; Moore et al., 2014).

En resumen, el conjunto de metabolitos que han sido asociados a la obesidad y diabetes pueden darnos información muy valiosa sobre las vías metabólicas alteradas durante el desarrollo de estas enfermedades. Además, estos metabolitos podrán ser utilizados en un futuro como biomarcadores para el diagnóstico de una enfermedad con el fin de dar un tratamiento más adecuado correspondiente a la vía metabólica afectada o bien podrán servir como indicadores para prevenir enfermedades que se puedan presentar en un futuro.

\section{Epigenómica}

Anteriormente, se pensaba que el ADN era una estructura simple y lineal. Sin embargo, en las últimas décadas se ha demostrado que el ADN puede plegarse formando estructuras tridimensionales que pueden regular regiones muy lejanas. La secuencia de nucleótidos, entonces, no es lo único que regula la expresión génica, sino el enrollamiento del ADN y su posicionamiento durante la formación de estructuras complejas que construyen a los cromosomas.

La epigenética se refiere al conjunto de procesos por medio de los cuales se regula la transcripción de los genes sin afectar la secuencia del ADN. Los mecanismos principales por los que se llevan a cabo estas regulaciones del genoma son la adición de grupos metilo (metilación) de los nucleótidos del ADN y la metilación o adición de grupos acetilo (acetilación) de las histonas (proteínas sobre 
las cuales se enrolla el ADN durante la formación de los cromosomas) (Burdge y Lillycrop, 2014; Desai, Jellyman y Ross, 2015). La epigenómica representa a los cambios epigenéticos globales en una muestra, en un momento dado y en condiciones fisiopatológicas específicas. Por ejemplo, un estudio reveló que la piel que ha sido expuesta al sol sin protección tiene, en su ADN, menos grupos metilos que la piel que ha sido protegida del sol (Vandiver et al., 2015). Los mismos patrones con menor cantidad de grupos metilo se han reconocido para las células cancerosas en comparación con las células sanas. Así, la epigenómica de la exposición al sol y de la progresión del cáncer son similares; esta similitud puede ser la respuesta molecular de cómo el cáncer de piel se asocia a la exposición al sol sin protección.

Las técnicas por medio de las cuales se estudia el epigenoma son muy diversas. En primer lugar, para conocer los patrones de metilación en el ADN, se utiliza frecuentemente la "secuenciación con bisulfito". También, se pueden emplear anticuerpos que se unan específicamente a los nucleótidos metilados para su reconocimiento (Han y He, 2016). En segundo lugar y para el caso de la modificación (metilación o acetilación) de histonas, se puede precipitar la cromatina utilizando anticuerpos que se unan específicamente a las histonas.

Un ejemplo muy interesante de la aplicación de la epigenómica a la clínica es la llamada programación fetal. Esta trata del destino metabólico de los hijos que han sido expuestos a ciertas condiciones nutricias durante el desarrollo en el útero. Las investigaciones del caso de la hambruna holandesa de 1944 nos permitieron ver que los niños nacidos de madres desnutridas tenían mayor tendencia a la obesidad y enfermedades metabólicas en la vida adulta (Ravelli, Stein y Susser, 1976). Ahora sabemos que tanto la desnutrición como la obesidad de la madre en la etapa fetal influyen sobre la salud metabólica del niño, del adolescente y del adulto más adelante en la vida (Reichetzeder et al., 2016). En diversos estudios se ha concluido que la dieta materna puede regular la transcripción de genes involucrados en la formación de tejido adiposo (adipogénesis), en la producción de lípidos (lipogénesis) y en el metabolismo de la glucosa. Un ejemplo de estos genes es el que codifica para la hormona leptina. La región que regula la transcripción del gen de la leptina tiene mayor número de grupos metilo después de consumir una dieta rica en grasas. Esta metilación incrementada provoca la disminución de la expresión del gen de leptina y, como consecuencia, existe menor concentración de esta hormona en suero (Milagro et al., 2009) Debido a que la acción de la leptina es favorecer la saciedad, su menor concentración promueve mayor consumo de alimento y contribuye a la formación de tejido adiposo y como consecuencia, la obesidad.

\section{Nutrigenómica y nutrigenética}

La nutrigenómica es la herramienta que nos deja conocer, de manera global, los cambios en la expresión de genes en respuesta al consumo de un nutrimento, 
alimento o dieta. Por ejemplo, se sabe que el consumo de ácidos grasos poliinsaturados (AGPI) resulta en un beneficio para la salud cardiovascular. En un estudio se determinó la influencia del AGPI docosahexanoico y sus metabolitos sobre la expresión global de genes y se concluyó que los genes que participan en la formación de la placa de ateroma que bloquea las arterias se encuentra disminuida (Merched et al., 2008). A partir de este tipo de trabajos, se ha visto que la dieta participa en los cambios de expresión de genes y que modifica el metabolismo.

Por otra parte, la nutrigenética se encarga de estudiar los efectos que tiene una variante genética sobre la respuesta del individuo a los nutrimentos. Existen referencias antiguas acerca de la variabilidad interindividual en respuesta a factores dietéticos, como la del poeta y filósofo griego Tito Lucrecio (99 a.C.-55 a.C.), quien citó: "Lo que para unos es comida, es amargo veneno para otros".

La profundización en el estudio de las enfermedades asociadas a las variantes genéticas ha generado un mejor entendimiento de la influencia de los nutrimentos y de la dieta sobre el estado de salud y enfermedad de los humanos. Un ejemplo clínico es la fenilcetonuria, la cual representa un error innato del metabolismo dado por la presencia de mutaciones en el gen que codifica para la enzima hidroxilasa de la fenilalanina (Neeha y Kinth, 2013). Como consecuencia, esta enzima no es funcional, provocando que el metabolismo de dicho aminoácido se vea afectado y se acumule el fenilpiruvato, un metabolito neurotóxico. Los pacientes con diagnóstico de fenilcetonuria deben consumir una dieta restringida en el aminoácido fenilalanina para evitar el acúmulo del metabolito neurotóxico, el cual provoca retraso mental.

Debido que la nutrigenética se basa en los cambios de variantes presentes en el ADN, los cuales influyen en la manera en que se metabolizan los nutrimentos, las metodologías utilizadas para determinar cuestiones de nutrigenética son las mismas que en genómica. Por otra parte, dado que la nutrigenómica estudia el impacto de los nutrimentos sobre la expresión de genes, las tecnologías utilizadas para su análisis son las mismas que las de la transcriptómica.

\section{Conclusiones}

Las "ómicas" representan el análisis de un gran número de moléculas a partir de muestras biológicas, gracias al avance tecnológico que se ha dado en los últimos años y a la formación de equipos multidisciplinarios que ayudan a la interpretación de los datos. La creación de los biobancos ha logrado recaudar un gran número de muestras, las cuales han sido analizadas desde las diferentes "ómicas" (genómica, transcriptómica, proteómica, metabolómica, nutrigenómica, epigenómica, entre otras) para poder obtener nueva información de un fenómeno biológico. Hasta ahora, nos hemos beneficiado de estas ciencias para la 
creación de biomarcadores que se asocian o predicen un proceso biológico, ya sea normal o que conlleva a una enfermedad.

Se ha logrado estudiar cada "ómica" por separado, pero el reto será interrelacionar a todas estas disciplinas. De esta forma, el estudio de las "ómicas" permitirá entender la red de moléculas y de procesos biológicos que estén involucrados en un proceso biológico o en una enfermedad. Cuando esto suceda, podremos utilizar la información para el oportuno diagnóstico de una enfermedad, para la generación de medicamentos más específicos y para la creación de la medicina personalizada, la cual busca individualizar la atención de los pacientes por medio de la predicción, prevención y tratamiento de las enfermedades, con el conocimiento de los antecedentes genéticos, la exposición ambiental y la alimentación de cada individuo.

En un futuro, los sistemas de salud podrán utilizar la información obtenida a partir de las "ómicas" para tratar los padecimientos más frecuentes de una población utilizando la medicina personalizada. Al mismo tiempo, se debe de contemplar que los datos generados por las "ómicas" deberán de respetar los aspectos éticos y legales establecidos por la legislación, con el fin de proteger el anonimato de los individuos. Por esta razón, se ha publicado recientemente una revisión del estatus de las regulaciones de los biobancos en México (MottaMurguia y Saruwatari-Zavala, 2016).

\section{Referencias}

* Avery, O. T., MacLeod, C. M., y McCarty, M. (1944). Studies on the chemical nature of the substance inducingtransformation of pneumococcal types. Journal of Experimental Medicine, 79(2), 137-158. DOI: http://doi.org/10.1084/jem.79.2.137.

* Bargalló-Rocha, J. E. et al. (2015). Cost-Effectiveness of the 21-Gene Breast Cancer Assay in Mexico. Advances in Therapy, 32(3), 239-253. DOI: http://doi.org/10.1007/ s12325-015-0190-8.

* Begum, F., Ghosh, D., Tseng, G. C. y Feingold, E. (2012). Comprehensive literature review and statistical considerations for GWAS meta-analysis. Nucleic Acids Research, 40(9), 3777-3784. DOl: http://doi.org/10.1093/nar/gkr1255.

Burdge, G. C. y Lillycrop, K. A. (2014). Environment-physiology, diet quality and energy balance: the influence of early life nutrition on future energy balance. Physiology y Behavior. DOI: http://doi.org/10.1016/j.physbeh.2013.12.007.

* Chevalier, S., Marliss, Morais, Lamarche y Gougeon (2005). Whole-body protein anabolic response is resistant to the action of insulin in obese women. American Journal of Clinical Nutrition, 82(2), 355-365. DOI: https://www.ncbi.nlm.nih.gov/pubmed.

* Corvol, H. et al. (2016). Translating the genetics of cystic fibrosis to personalized medicine. s. DOI: http://doi.org/10.1016/j.trsl.2015.04.008. 
* Desai, M., Jellyman, J. K. y Ross, M. G. (2015). Epigenomics, gestational programming and risk of metabolic syndrome. International Journal of Obesity. DOI: http:// doi.org/10.1038/ijo.2015.13.

* Fiehn, O., Timothy Garvey, W., Newman, J. W., Lok, K. H., Hoppel, C. L. y Adams, S. H. (2010). Plasma metabolomic profiles reflective of glucose homeostasis in non-diabetic and type 2 diabetic obese African-American women. PLOS ONE, 5(12), 1-10. DOI: http://doi.org/10.1371/journal.pone.0015234.

Gutierrez Aguilar, R., Kim, D. H., Woods, S. C. y Seeley, R. J. (2011). Expression of New Loci Associated With Obesity in Diet-Induced Obese Rats: From Genetics to Physiology. Obesity (Silver Spring). DOI: https://doi.org/10.1038/oby.2011.236.

- Han, Y. y He, X. (2016). Integrating epigenomics into the understanding of biomedical insight. Bioinformatics and Biology Insights. Recuperado de: https://www.ncbi. nlm.nih.gov/pmc/articles/PMC5138066/.

* Harrow, J. et al. (2012). GENCODE: The reference human genome annotation for the ENCODE project. Genome Research, 22(9), 1760-1774. DOI: http://doi.org/10.1101/ gr.135350.111.

* Hershey, A. D. y Chase, M. (1952). Independent functions of viral protein and nucleic acid in growth of bacteriophage. Journal of General Physiology, 36(1), 39-56. Reciperado de: https://www.ncbi.nlm.nih.gov/pmc/articles/PMC2147348/.

* International Human Genome Sequencing Consortium. (2004). International Human Genome Sequencing Consortium. Finishing the euchromatic sequence of the human genome. Nature, 431, 931-945. Recuperado de: $\quad$ http://www.nature.com/nature/journal/v431/n7011/full/nature03001. html?foxtrotcallback=true.

* Kosteria, I. et al. (2017). The use of proteomics in assisted reproduction. In Vivo, 31(3), 267-283. DOl: http://doi.org/10.21873/invivo.11056.

- LaFramboise, T. (2009). Single nucleotide polymorphism arrays: A decade of biological, computational and technological advances. Nucleic Acids Research. DOI: http://doi.org/10.1093/nar/gkp552.

- Manolio, T. A. (2010). Genomewide Association Studies and Assessment of the Risk of Disease. The New Eng/and Journal of Medicine, 363(2), 166-176. DOI: http:// doi.org/10.1056/NEJMra0905980.

* Merched, A. J. et al. (2008). Atherosclerosis: evidence for impairment of resolution of vascular inflammation governed by specific lipid mediators. The FASEB Journal, 22(10), 3595-3606. DOI: http://doi.org/10.1096/fj.08-112201.

* Milagro, F. I. et al. (2009). High fat diet-induced obesity modifies the methylation pattern of leptin promoter in rats. Journal of Physiology and Biochemistry, 65(1), 1-9. Rrecuperado de: http://www.ncbi.nlm.nih.gov/pubmed/19588726.

- Mishra, N. (2010). Introduction to Proteomics: Principles and Applications. Introduction to Proteomics: Principles and Applications. DOI: http://doi. org/10.1002/9780470603871. 
* Moore, S. C. et al. (2014). Human metabolic correlates of body mass index. Metabolomics, 10(2), 259-269. DOI: http://doi.org/10.1007/s11306-013-0574-1.

* Moran-Ramos, S. et al. (2017). An amino acid signature associated with obesity predicts 2-year risk of hypertriglyceridemia in school-age children. Scientific Reports. Recuperado de: https://www.nature.com/articles/s41598-017-05765-4.

* Motta Murguia, L. y Saruwatari-Zavala, G. (2016). Mexican Regulation of Biobanks. The Journal of Law, Medicine y Ethics: A Journal of the American Society of Law, Medicine y Ethics, 44(1), 58-67. Recuperado de: https://www.ncbi.nlm.nih.gov/pubmed/27256124.

* Neeha, V. S. y Kinth, P. (2013). Nutrigenomics research: A review. Journal of Food Science and Technology, 50(3), 415-428. DOI: http://doi.org/10.1007/s13197-012$\underline{0775-z .}$

- Omenn, G. S. et al. (2015). Metrics for the human proteome project 2015: Progress on the human proteome and guidelines for high-confidence protein identification. Journal of Proteome Research, 14(9), 3452-3460. DOI: http://doi.org/10.1021/ acs.jproteome.5b00499.

* Park, S., Sadanala, K. C. y Kim, E.-K. (2015). A Metabolomic Approach to Understanding the Metabolic Link between Obesity and Diabetes. Molecules and Cells. DOI: http://doi.org/10.14348/molcells.2015.0126.

Ravelli, G. P., Stein, Z. A. y Susser, M. W. (1976). Obesity in Young Men after Famine Exposure in Utero and Early Infancy. New England Journal of Medicine, 295(7), 349-353. DOI: http://doi.org/10.1056/NEJM197608122950701.

* Reichetzeder, C. et al. (2016). Developmental Origins of Disease - Crisis Precipitates Change. Cellular Physiology and Biochemistry, 39(3), 919-938. DOI: http://doi. org/10.1159/000447801.

* Vandiver, A. R., Irizarry, R. Hansen, K, Garza, L., Runarsson, A., Li, X., Chien, A., Wang, T., Leung, S. Kang, S y Feinberg, A. (2015). Age and sun exposure-related widespread genomic blocks of hypomethylation in nonmalignant skin. Genome Biology. DOI: https://doi.org/10.1186/s13059-015-0644-y.

* Venter, J. C. et al. (2001). The sequence of the human genome. Science, 291(5507), 1304-1351. DOI: http://doi.org/10.1126/science.1058040.

* Watson, J. D. y Crick, F. H. C. (1953). Molecular structure of nucleic acids. Nature. DOI: http://doi.org/10.1097/BLO.0b013e3181468780.

\section{Cómo citar este artículo}

* Frigolet, Maria E. y Gutiérrez-Aguilar, Ruth (2017). Ciencias "ómicas", ¿cómo ayudan a las ciencias de la salud? Revista Digital Universitaria (RDU), vol. 18, núm. 7, septiembre-octubre. DOI: http://dx.doi.org/10.22201/codeic.16076079e.2017.v18n7.a3. 